\title{
Effects of Hole Perpendicularity Error on Mechanical Performance of Single-Lap Double-Bolt Composite Joints
}

\author{
Xueshu Liu, ${ }^{1}$ Yuxing Yang, ${ }^{2}$ Yiqi Wang, ${ }^{2}$ Yongjie Bao, ${ }^{2}$ and Hang Gao ${ }^{2}$ \\ ${ }^{1}$ School of Automotive Engineering, Dalian University of Technology, Dalian 116024, China \\ ${ }^{2}$ School of Mechanical Engineering, Dalian University of Technology, Dalian 116024, China \\ Correspondence should be addressed to Xueshu Liu; liuxs@dlut.edu.cn
}

Received 9 August 2017; Revised 10 October 2017; Accepted 7 November 2017; Published 27 November 2017

Academic Editor: Peng He

Copyright ( 2017 Xueshu Liu et al. This is an open access article distributed under the Creative Commons Attribution License, which permits unrestricted use, distribution, and reproduction in any medium, provided the original work is properly cited.

\begin{abstract}
Static tensile experiments and numerical simulations were carried out to study effects of hole perpendicularity error on mechanical performance of single-lap double-bolt composite joints. Hole tilting angle, varying from 1 to 4 degrees, and hole tilting direction to account for anisotropic properties of composite material were investigated. Progressive damage model (PDM) based on ChangLessard type criterion with an extension by Olmedo was created, which involved seven failure modes and made material properties be a direct function of predefined field variables. The model was implemented in ABAQUS/Standard using a UMAT subroutine. Good agreement was found when comparing numerical simulation results with experimental outcomes. In addition, the results demonstrate that, with increasing of hole tilting angle, damage is prone to arise and the load path of the composite bolted joints alters with changing of hole tilting direction, which result in severe stress concentration around the edge of hole and joint failure in advance.
\end{abstract}

\section{Introduction}

Designable combinations of fiber and matrix make the composite a versatile material. Their high strength coupled with light weight leads to their use wherever structural efficiency is at a premium. However, joints are always necessary to manufacture a large composite structure, among which bonded joints become increasingly common in automotive and marine field due to their ability to improve structural performance and help weight reduction [1-3]. Nevertheless, when load-carrying capacity is concerned, bolted joints are the most important methods of composite assembling especially in aerospace industry because of their high loadcarrying capacity and facility to assemble, disassemble, and repair. For such a joint, it is essential to machine the composite laminates with the utilization of, for example, drills, and thus the structure integrity of composite laminate is broken, which results in stress concentration around the edge of hole and a significant reduction of the load-carrying capacity. Therefore, the bolted joint is a key point of the composite structural design.
The main purpose of studies on composite bolted joints is to determine the effect of various parameters on joint strength. Theoretical results are also used to serve the improvement of bolted joint design and exploit the full potential of CFRP. Unsustainable and conservative design can therefore be avoided with methods that have been benchmarked against satisfactory data. The parameters that have been studied include geometrical factors $[4,5]$, fastener parameters [6], material properties [7, 8], application factors [9], and manufacturing process [10-12].

The process factors determine the structural parameters of composites, the physical-mechanical properties, and the residual stresses produced by assembly process. Typical process factors include the bolt hole clearance effects, the accuracy and interchangeability of the joints, and the machining quality of the holes. Many factors have been studied by scholars except for hole perpendicularity error. In this paper, hole perpendicularity error is taken into consideration to enrich the study of composite bolted joints. Finite element analysis (FEA) and experiments were carried out and compared to assess the mechanical performance of composite joints. 


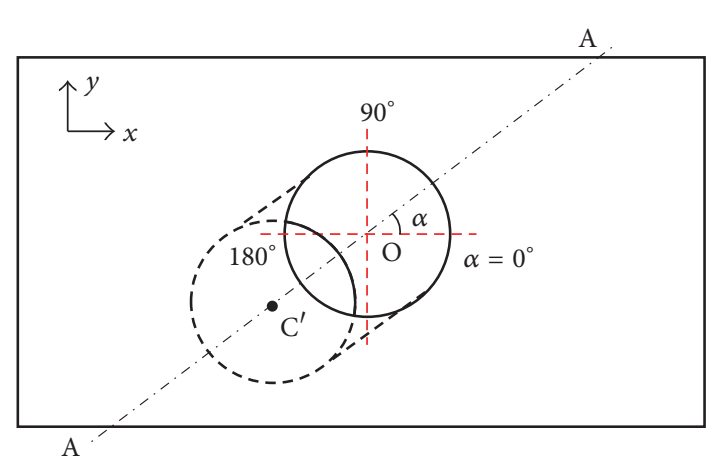

(a)

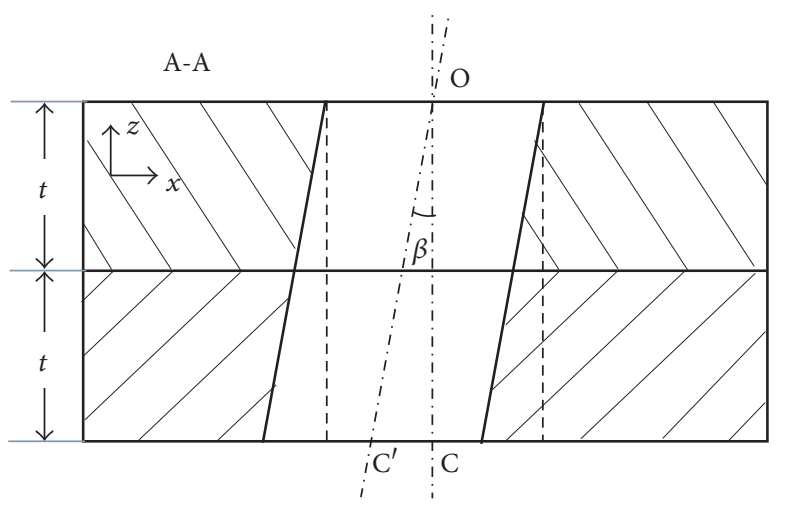

(b)

FIGURE 1: Characterization of perpendicularity error of hole from [9].

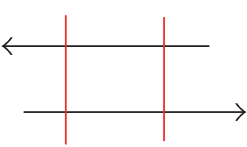

(a) P0

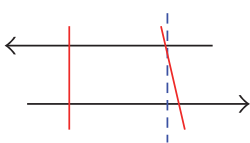

(b) P1

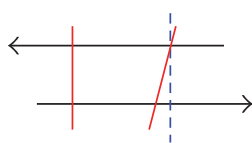

(c) P2

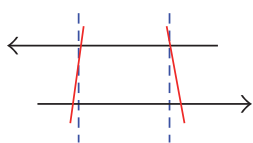

(d) P3

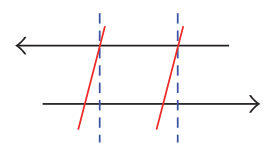

(e) P4

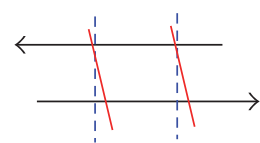

(f) P5

Figure 2: Patterns of single-lap double-bolt joints.

\section{Problem Description}

Hole perpendicularity error is a kind of manufacturing defects, which results in stress concentration around hole edge area. In the case of single-lap single-bolt composite joint, the appearance of hole perpendicularity error will lead to bearing capability decrease of the bolted joint [12]. However, composite parts are often assembled with multiple bolts in engineering applications. Bolt holes with perpendicularity errors will affect each other, which eventually influences the mechanical performance of the joint. In this paper, by designing and carrying out tensile test for single-lap double-bolt composite joints, the bearing capacity and failure mode of the joints were obtained, and the effects of hole perpendicularity error on the joint performance were investigated.

Considering the anisotropic properties of CFRP, two parameters are used to characterize the hole perpendicularity error, tilting direction $\alpha$ and tilting angle $\beta$, as shown in Figure 1. Project the hole on a plane, say $X Y$, where $X$ is the longitudinal direction of the specimen. The initial side of $\alpha$ is on the positive $x$-axis and the terminal one is on $\mathrm{OC}^{\prime}$, namely, the projection of bolt hole center axis (Figure 1(a)), with positive angles representing rotations toward the positive $y$-axis. In the case where the plate thickness $t$ is constant, the angle between the bolt hole center axis, $\mathrm{OC}^{\prime}$, and the theoretical one, OC, is used to characterize the magnitude of hole perpendicularity error (Figure 1(b)).

Only tilting directions $\alpha=0^{\circ}$ and $\alpha=180^{\circ}$ are discussed to reduce the parameters of the study. The influence of tilting direction for double-bolt composite joints can be classified into 6 different patterns after taking into account the symmetry of the structure. The diagrammatic sketches are demonstrated in Figure 2, where red lines indicate bolts and the black arrows represent the laminates and their loading directions.

\section{Methodology}

3.1. Specimens and Experimental Procedures. The specimens used in this study were manufactured from IMS194/ CYCOM977-2 carbon fiber/epoxy prepreg (nominal ply thickness is $0.188 \mathrm{~mm}$ ) and designed to fail initially in the bearing mode with symmetric stacking sequence of $[-45 / 0 /$ $45 / 90 / 0 / 90 / 45 / 0 /-45 / 45]_{S}$. The material properties provided by the manufacturer are shown in Table 1 . Protruding head bolts made of SCM35 alloy steel are used as fasteners, whose elastic modulus and Poisson ratio are, respectively, $190 \mathrm{GPa}$ and 0.3. The elasticity and Poisson's ratio of nuts and gaskets are the same as those of bolts. The plastic behavior of the SCM35 alloy steel is given in Table 2.

Single-lap double-bolt composite joints were prepared according to the ASTM standard D5961/D5661 M-13 with width-to-hole diameter ratio $(w / d=6)$ and edge distanceto-hole diameter ratio $(e / d=3)$ [13]. Standard specimen configurations using fixed values of test parameters are shown in Figure 3.

According to the ASTM D5961 standard, the static tensile tests were performed on a WDW-100 testing machine in displacement control at a rate of $1.0 \mathrm{~mm} / \mathrm{min}$. The experimental setup is shown in Figure 4. The displacement was recorded using a YSJ50-5-ZC extensometer with a gauge length of $50 \mathrm{~mm}$ and measure range of $12.5 \mathrm{~mm}$. The loading procedure is not stopped until the load has dropped off about 30\% after it reaches the maximum, or displacement exceeds the extensometer range. A preload torque of $7.1 \mathrm{Nm}$ was applied to both bolts. The configurations of test are shown in Table 3 


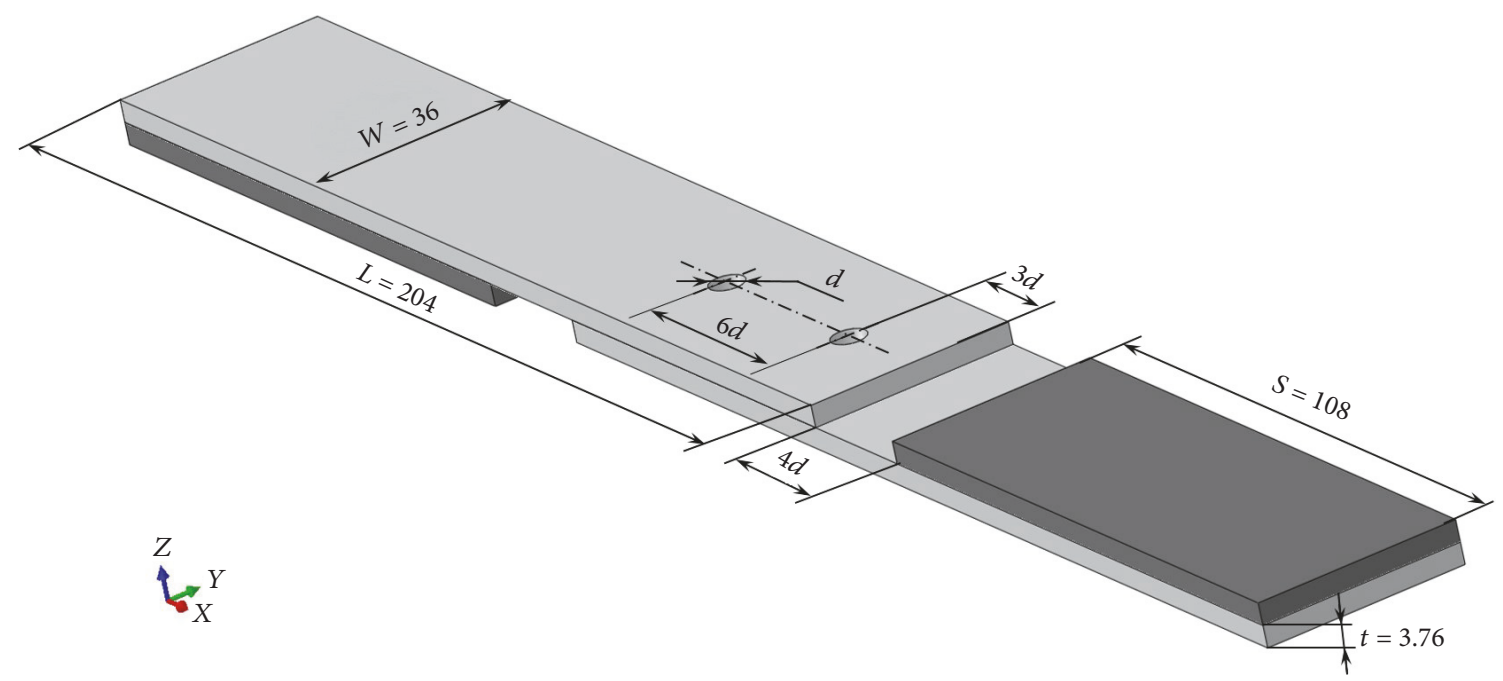

FIgURE 3: Configuration of specimens (unit: $\mathrm{mm}$ ).

TABLE 1: Mechanical properties of IMS194/CYCOM977-2.

\begin{tabular}{lccc}
\hline Elastic property & Value & Strength property & Value \\
\hline$E_{1} / \mathrm{GPa}$ & 165 & $X_{T} / \mathrm{MPa}$ & 3150 \\
$E_{2} / \mathrm{GPa}$ & $8.17^{*}$ & $X_{C} / \mathrm{MPa}$ & 1450 \\
$E_{3} / \mathrm{GPa}$ & $8.17^{*}$ & $Y_{T} / \mathrm{MPa}$ & $81.4^{*}$ \\
$G_{12} / \mathrm{GPa}$ & 4.27 & $Y_{C} / \mathrm{MPa}$ & $270^{*}$ \\
$G_{13} / \mathrm{GPa}$ & $4.27^{*}$ & $Z_{T} / \mathrm{MPa}$ & $81.4^{*}$ \\
$G_{23} / \mathrm{GPa}$ & 2.52 & $Z_{C} / \mathrm{MPa}$ & $270^{*}$ \\
$v_{12}$ & 0.33 & $S_{12} / \mathrm{MPa}$ & 108 \\
$v_{13}$ & $0.33^{*}$ & $S_{13} / \mathrm{MPa}$ & 108 \\
$v_{23}$ & 0.55 & $S_{23} / \mathrm{MPa}$ & 108 \\
\hline
\end{tabular}

${ }^{*}$ This value is set according to the transversely isotropic assumption and engineering experience.

TABLE 2: Plastic behavior of SCM35 alloy steel.

\begin{tabular}{lc}
\hline Stress/GPa & Plastic strain \\
\hline 0.63 & 0 \\
0.76 & 0.01 \\
1.08 & 0.05 \\
1.13 & 0.08 \\
1.2 & 0.1 \\
\hline
\end{tabular}

and the group is marked as " $\mathrm{Pi}-\beta-(F)$," where "Pi" indicates the pattern as shown in Figure 2, $\beta$ means hole tilting angle, and $F$, if there is any, represents the maximum load applied to the joint during test. Otherwise, the joint will be loaded until its failure. Note that $30 \mathrm{kN}$ is about $80 \%$ of the failure load of the single-lap double-bolt composite joint.

3.2. Numerical Model. To investigate the effects of hole perpendicularity error on mechanical behavior of single-lap double-bolt composite joints, a nonlinear three-dimensional
TABLE 3: Test groups and parameters.

\begin{tabular}{lccc}
\hline Group & Pattern & $\beta /^{\circ}$ & Repeat \\
\hline P0-0 & P0 & 0 & 3 \\
P0-0-30 & P0 & 0 & 1 \\
P1-4 & P1 & 4 & 3 \\
P1-4-30 & P1 & 4 & 1 \\
P2-2 & P2 & 2 & 3 \\
P2-4 & P2 & 4 & 3 \\
P2-4-30 & P2 & 4 & 1 \\
\hline
\end{tabular}

finite element model was constructed with 8-node solid element C3D8R using the commercial finite element software, ABAQUS [14], as illustrated in Figure 5.

To reduce the computational cost, the grip area of the composite laminate was neglected and the laminate was modelled with 5 elements in thickness direction, which avoids excessive width-to-thickness ratio of the element [7].

Contact interactions between all surfaces were modelled by surface-based contact considering the linear penalty method. Seventeen contact interactions with finite sliding formulation were defined to simulate the interfaces between any two parts. The stiffness of master surface was relatively larger and the meshes were designed to be coarser than those of slave surfaces. Default contact control and contact stabilization were defined for each contact pair to improve convergence. Constant value of friction coefficient was set to $0.3[8]$.

Boundary conditions were applied to reference points, which defined coupling constraints to node sections in the FEA model as shown in Figure 5. Section A was limited by three displacement degrees of freedom, while displacement load was applied to section B in $X$ direction with the other two displacement degrees of freedom fixed. A preload force of $6 \mathrm{kN}$ is applied to the bolt shank by "bolt load" function. 


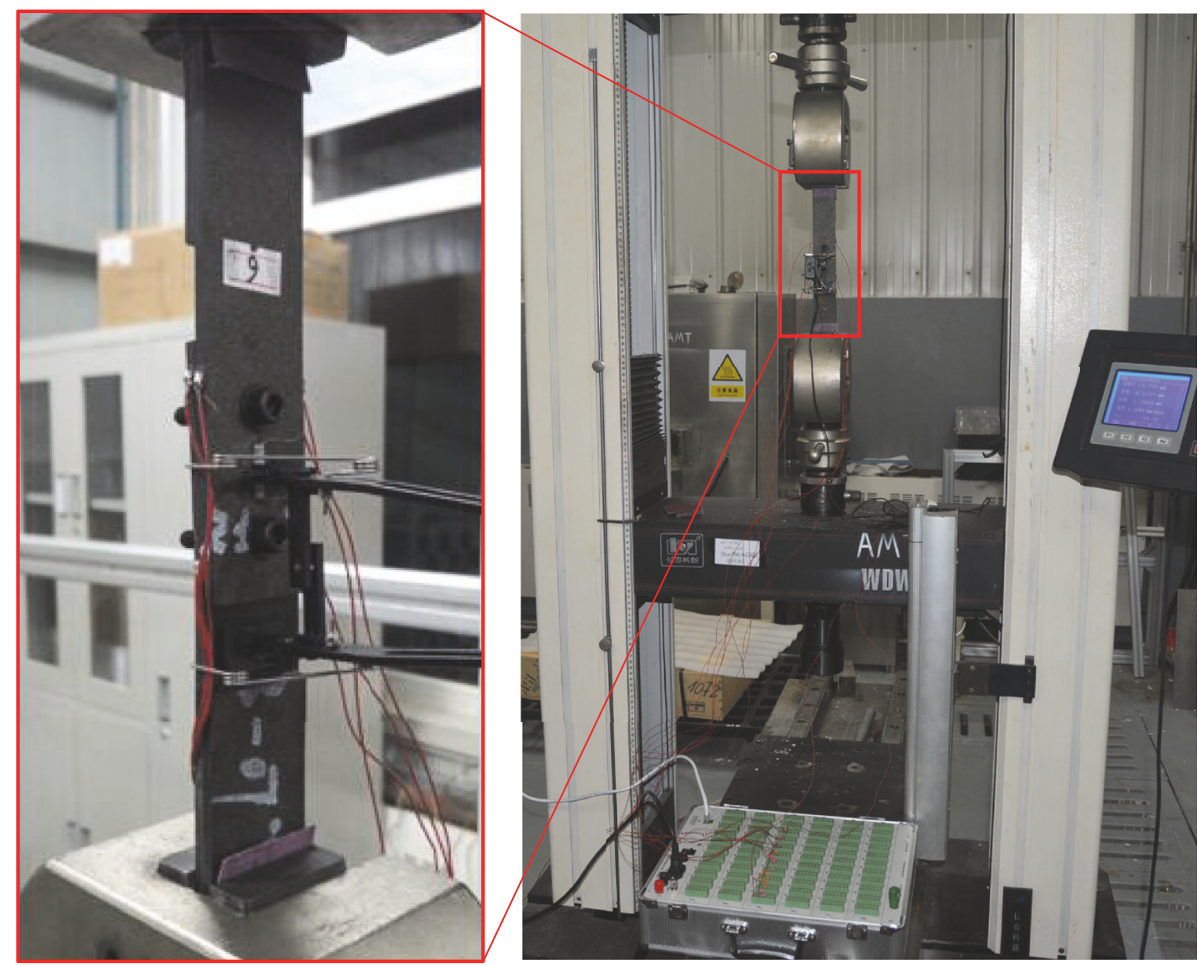

FIGURE 4: Experimental setup.

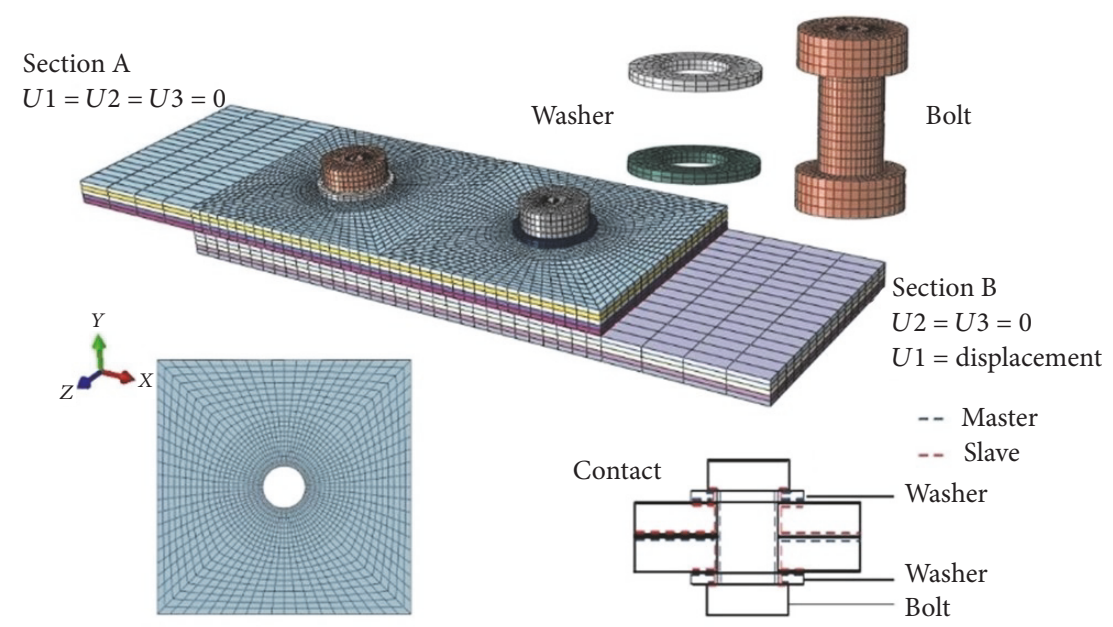

FIgURE 5: FEA model and interactions of bolted joint.

There were 42,272 elements in total in the finite element model. Considering that the region around the hole is the key area of stress concentration, the size of refined meshes was approximately $0.36 \times 0.77 \mathrm{~mm}$ in the vicinity of the hole in order to ensure the accuracy. Coarser meshes were adopted further to reduce computational cost. The element size of bolts and washers was set up corresponding to the size of the contact areas of the laminates.

The progressive damage method has attracted extensive attention in analysis and design of composite structures, which effectively simulates damage formation, evolution, and ultimate failure process of complex composite structures. Unlike isotropic materials, the destruction of composite materials is a gradual process. The progressive damage method is based on damage mechanics, which regards the failure of composite materials as damage. The material degradation model was used to describe the mechanical behavior of damaged material.

The progressive damage analysis includes the stress solving of the nonlinear finite element equilibrium equation, the 
prediction of damage initiation, damage evolution, and the stiffness degradation based on the material failure criterion. Stress analysis is mainly carried out by finite element software and has evolved from two-dimensional model into threedimensional model. There are diverse failure criteria to predict the damage initiation including Chang criteria [15], TsaiWu criteria [16], Hashin type criteria [17], and Puck criteria [18]. In this paper, a damage model considering the effect of nonlinear shear stress-strain behavior was established based on extended Chang-Lessard type criteria $[19,20]$. Seven basic microscopic failure modes in composite were detected and distinguished by utilizing the failure criterion, as illustrated in (1)-(7).

Tensile fiber failure, $\sigma_{11}>0$ :

$$
\begin{gathered}
\left(\frac{\sigma_{1}}{X_{T}}\right)^{2}+\frac{\tau_{12}^{2} / 2 G_{12}+(3 / 4) \alpha \tau_{12}^{4}}{S_{12}^{2} / 2 G_{12}+(3 / 4) \alpha S_{12}^{4}} \\
+\frac{\tau_{13}^{2} / 2 G_{12}+(3 / 4) \alpha \tau_{13}^{4}}{S_{13}^{2} / 2 G_{13}+(3 / 4) \alpha S_{13}^{4}} \geq 1 .
\end{gathered}
$$

Compressive fiber failure, $\sigma_{11}<0$ :

$$
\left(\frac{\sigma_{1}}{X_{C}}\right)^{2} \geq 1
$$

Fiber-matrix shear-out failure, $\sigma_{11}<0$ :

$$
\begin{gathered}
\left(\frac{\sigma_{1}}{X_{C}}\right)^{2}+\frac{\tau_{12}^{2} / 2 G_{12}+(3 / 4) \alpha \tau_{12}^{4}}{S_{12}^{2} / 2 G_{12}+(3 / 4) \alpha S_{12}^{4}} \\
+\frac{\tau_{13}^{2} / 2 G_{13}+(3 / 4) \alpha \tau_{13}^{4}}{S_{13}^{2} / 2 G_{13}+(3 / 4) \alpha S_{13}^{4}} \geq 1 .
\end{gathered}
$$

Matrix cracking failure, $\sigma_{22}<0$ :

$$
\begin{gathered}
\left(\frac{\sigma_{2}}{Y_{T}}\right)^{2}+\frac{\tau_{12}^{2} / 2 G_{12}+(3 / 4) \alpha \tau_{12}^{4}}{S_{12}^{2} / 2 G_{12}+(3 / 4) \alpha S_{12}^{4}} \\
+\frac{\tau_{23}^{2} / 2 G_{23}+(3 / 4) \alpha \tau_{23}^{4}}{S_{23}^{2} / 2 G_{23}+(3 / 4) \alpha S_{23}^{4}} \geq 1 .
\end{gathered}
$$

Matrix crushing failure, $\sigma_{22}>0$ :

$$
\begin{gathered}
\left(\frac{\sigma_{2}}{Y_{C}}\right)^{2}+\frac{\tau_{12}^{2} / 2 G_{12}+(3 / 4) \alpha \tau_{12}^{4}}{S_{12}^{2} / 2 G_{12}+(3 / 4) \alpha S_{12}^{4}} \\
+\frac{\tau_{23}^{2} / 2 G_{23}+(3 / 4) \alpha \tau_{23}^{4}}{S_{23}^{2} / 2 G_{23}+(3 / 4) \alpha S_{23}^{4}} \geq 1 .
\end{gathered}
$$

Delamination onset in tension, $\sigma_{33}>0$ :

$$
\begin{gathered}
\left(\frac{\sigma_{3}}{Z_{T}}\right)^{2}+\frac{\tau_{13}^{2} / 2 G_{12}+(3 / 4) \alpha \tau_{13}^{4}}{S_{13}^{2} / 2 G_{13}+(3 / 4) \alpha S_{13}^{4}} \\
+\frac{\tau_{23}^{2} / 2 G_{23}+(3 / 4) \alpha \tau_{23}^{4}}{S_{23}^{2} / 2 G_{23}+(3 / 4) \alpha S_{23}^{4}} \geq 1 .
\end{gathered}
$$

Delamination onset in compression, $\sigma_{33}<0$ :

$$
\begin{gathered}
\left(\frac{\sigma_{3}}{Z_{C}}\right)^{2}+\frac{\tau_{13}^{2} / 2 G_{13}+(3 / 4) \alpha \tau_{13}^{4}}{S_{13}^{2} / 2 G_{13}+(3 / 4) \alpha S_{13}^{4}} \\
+\frac{\tau_{23}^{2} / 2 G_{23}+(3 / 4) \alpha \tau_{23}^{4}}{S_{23}^{2} / 2 G_{23}+(3 / 4) \alpha S_{23}^{4}} \geq 1,
\end{gathered}
$$

where $\sigma_{i}(i=1,2,3)$ are the scalar components of the stress tensor; $X_{T}, X_{C}, Y_{T}, Y_{C}, Z_{T}$, and $Z_{C}$ are normal strength, in which subscripts " $t$ " and " $c$ " denote tensile and compressive status, respectively; and $S_{i j}(i, j=1,2,3)$ are shear strength. $\alpha$ is a constant parameter which was determined experimentally and set as $2.44 \times 10^{-8}$.

The composite laminates are subjected to gradual increasing load. Once the stress matches the equations of failure criteria, damage occurs. The mechanical properties of the material elements in the damaged area will be degenerated with a sudden drop and the degradation rules are given in Table 4.

There are no acknowledged degradation criteria of material property. Most of them are determined based on experiments and experience. The sudden drop degradation model is relatively easy to implement and thus is widely used in the progressive damage analysis of composites. Tan [21], F.-K. Chang and K.-Y. Chang [22], Camanho and Matthews [23], McCarthy et al. [24], and Tserpes et al. [25] put forward different degradation models, which match the specific failure criteria, respectively.

\section{Results}

4.1. Model Validation. Figure 6 shows the load-displacement curves of experimental results and FEA one of P0. It can be found that all results show the same tendency. In addition, the ultimate bearing load is about $38 \mathrm{kN}$, which proves that the numerical result is reliable when bearing load is concerned.

As shown in Table 5, the average ultimate loads of P0, P14, and $\mathrm{P} 2-4$ are $38387 \mathrm{~N}, 37737 \mathrm{~N}$, and $37745 \mathrm{~N}$, respectively. The difference is less than $2 \%$, which indicates that when hole perpendicularity error is less than $4^{\circ}$, it has limited influence on ultimate load of single-lap double-bolt joints. The numerical prediction for ultimate load of the joint is $35900 \mathrm{~N}$. The errors of the ultimate load and stiffness between the experimental outcomes and FEA results are about $6.5 \%$ and $12.5 \%$, which demonstrates that the PDM can be used to predict the failure loads of composite joints.

Figure 7 shows the experimental damage morphology of the top laminate of P1. It can be seen that the laminate mainly experienced bearing damage. Fiber breakage mainly happened around the bolt hole and in the transvers direction of the laminate. In addition, the bearing failure of fiber and matrix mainly occurred on the contact surface of the bolt shank and the hole. Both mentioned damage occurrences were perfectly predicted by numerical simulation. As shown in Figure 8, tensile fiber failure (SDV1), compressive fiber failure (SDV2), tensile matrix failure (SDV3), and matrix crushing failure (SDV4) appeared perfectly at the corresponding zones. Moreover, the region of bearing damage could be identified by the uplift of the material around the holes and 
TABLE 4: Material property degradation for each failure criterion.

\begin{tabular}{lc}
\hline Model of failure & Material properties degradation rules \\
\hline Matrix cranking failure & $E_{2}^{\prime}=0.1 E_{2}, G_{12}^{\prime}=0.1 G_{12}, G_{23}^{\prime}=0.1 G_{23}, v_{12}^{\prime}=0.1 v_{12}, v_{23}^{\prime}=0.1 v_{23}$ \\
Matrix crushing failure & $E_{2}^{\prime}=0.2 E_{2}, G_{12}^{\prime}=0.2 G_{12}, G_{23}^{\prime}=0.2 G_{23}, v_{12}^{\prime}=0.2 v_{12}, v_{23}^{\prime}=0.1 v_{23}$ \\
Tensile fiber failure & $E_{1}^{\prime}=0.02 E_{1}, v_{12}^{\prime}=0.02 v_{12}$ \\
Compressive fiber failure & $E_{1}^{\prime}=0.04 E_{1}, v_{12}^{\prime}=0.04 v_{12}$ \\
Fiber-matrix shear-out failure & $G_{12}^{\prime}=0.02 G_{12}, v_{12}^{\prime}=0.02 v_{12}$ \\
Delamination onset in tension & $E_{3}^{\prime}=0.02 E_{3}, G_{12}^{\prime}=0.02 G_{12}, G_{23}^{\prime}=0.02 G_{23}, v_{12}^{\prime}=0.02 v_{12}, v_{23}^{\prime}=0.02 v_{23}$ \\
Delamination onset in compression & $E_{2}^{\prime}=0.2 E_{2}, G_{12}^{\prime}=0.2 G_{12}, G_{23}^{\prime}=0.2 G_{23}, v_{12}^{\prime}=0.2 v_{12}, v_{23}^{\prime}=0.1 v_{23}$ \\
\hline
\end{tabular}

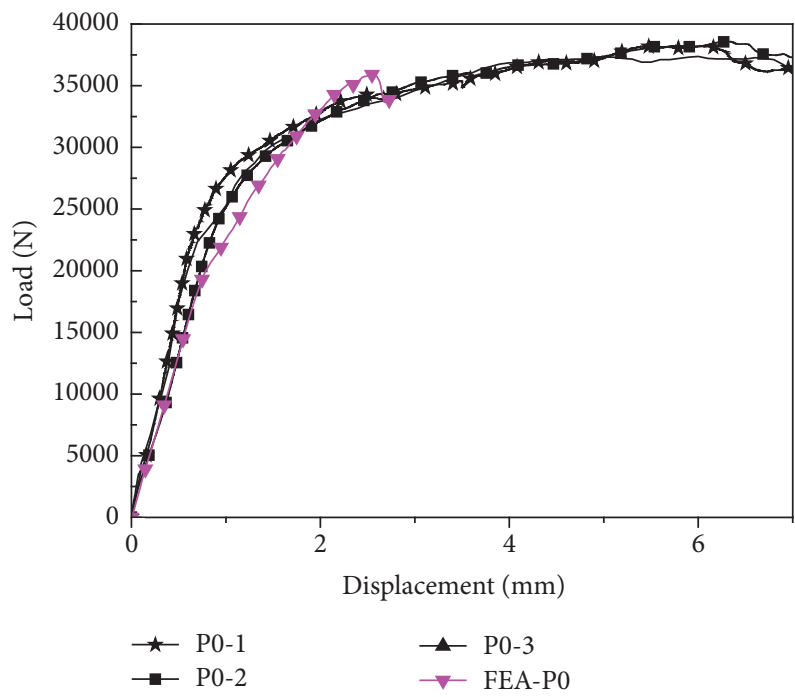

FIgURE 6: Comparison of numerical and experimental load-displacement curves.

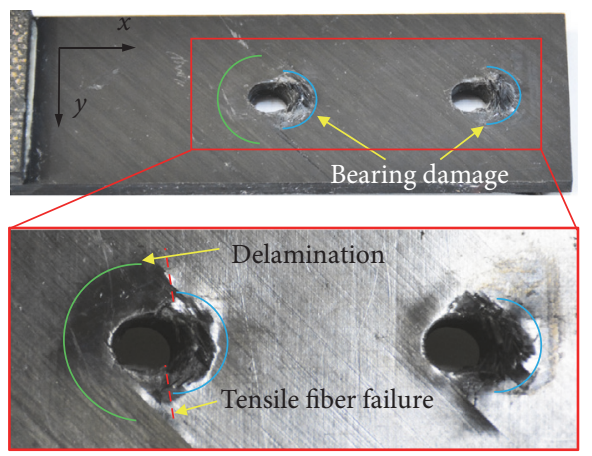

FIGURE 7: Failure morphology of the top laminate under failure load.

it extended about half of the hole diameter from the wall of the hole (Figure 7, light blue curves). Similar results were obtained as given in Figures 8(b) and 8(d). Finally, delamination caused by secondary bending of the single-lap joint occurred around the hole and close to the loading side (green curves in Figure 7), which was also successfully predicted by the proposed model (Figure $8(\mathrm{f})$ ).
TABLE 5: The experimental and numerical bearing behaviors of all specimens.

\begin{tabular}{lcccc}
\hline Group & $\begin{array}{c}\text { Stiffness } \\
(\mathrm{N} / \mathrm{mm})\end{array}$ & $\begin{array}{c}\text { Mean } \\
(\mathrm{N} / \mathrm{mm})\end{array}$ & $\begin{array}{c}\text { Ultimate load } \\
(\mathrm{N})\end{array}$ & $\begin{array}{c}\text { Mean } \\
(\mathrm{N})\end{array}$ \\
\hline P0-0 & 33289 & & 38206 & \\
P0-0 & 30424 & 30711 & 38568 & 38047 \\
P0-0 & 28421 & & 37367 & \\
P1-4 & 31889 & & 37800 & \\
P1-4 & 30964 & 31181 & 37668 & 37734 \\
P1-4 & 30691 & & 37976 & \\
P2-2 & 26500 & & 38894 & \\
P2-2 & 28673 & 28083 & 37783 & 37450 \\
P2-2 & 29076 & & 35671 & \\
P2-4 & 27171 & & 37964 & \\
P2-4 & 25804 & 26540 & 37526 & 37745 \\
P2-4 & 26645 & & 37535 & \\
FEA-P0 & - & 36690 & - & 35900 \\
\hline
\end{tabular}

Bearing failure of composite laminate is a combination of multiple damage occurrences. When subjected to tensile loading, the bolt shank is pressed against the bolt hole. Then, the fibers firstly bear the load due to their larger elastic modulus and are gradually buckling as the load increases until fracture. After that, matrix compression failure and fiber-matrix shear-out failure occur along with delamination between layers. Gradually, as fiber and matrix failures continue to expand, the load-carrying capacity of the composite laminates decreases.

4.2. Parameters Study. In this section, how the load-carrying capacity of a single-lap double-bolt joint is affected will be discussed. Numerical results are shown in Figure 9 and details are given in Table 6. Generally speaking, both stiffness and ultimate load of the joints have a tendency to decrease with increasing of tilting angle. However, the decline of stiffness is larger than that of ultimate load, which indicates that hole perpendicularity error has a great influence on joint stiffness.

As shown in Figure 9(a), the linear elastic segments of load-displacement curves are substantially coincident for P1. The deviations of stiffness and ultimate load are less than $3 \%$ 

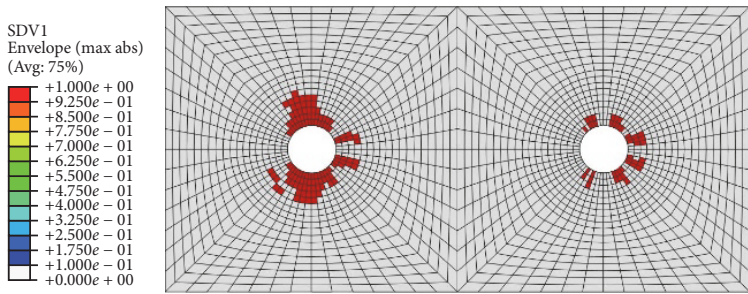

(a) Tensile fiber failure (SDV1)
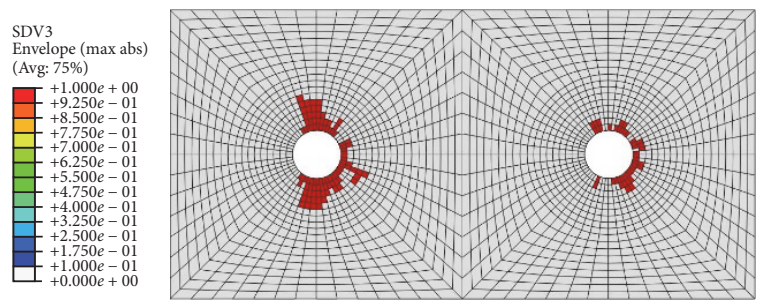

(c) Tensile matrix failure (SDV3)
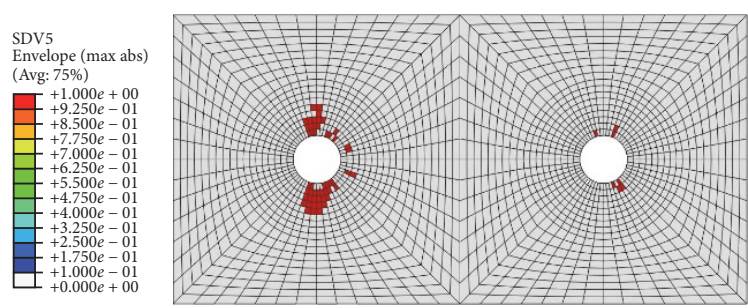

(e) Delamination onset in tension (SDV5)
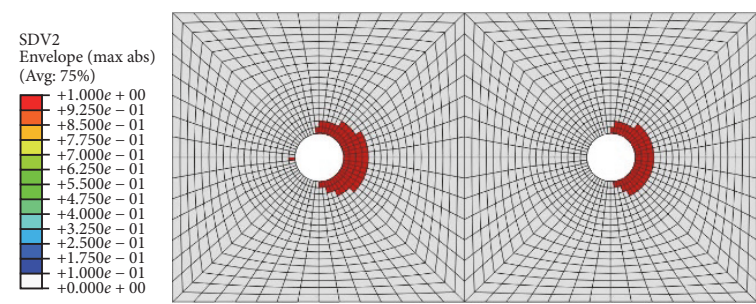

(b) Compressive fiber failure (SDV2)
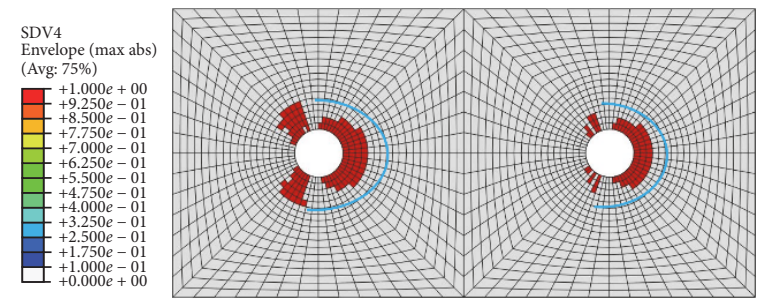

(d) Compressive matrix failure (SDV4)
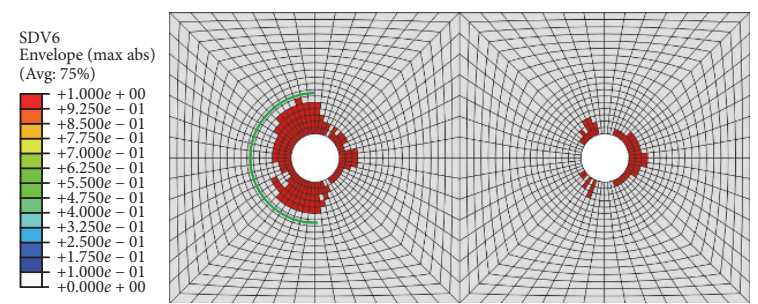

(f) Delamination onset in compression (SDV6)
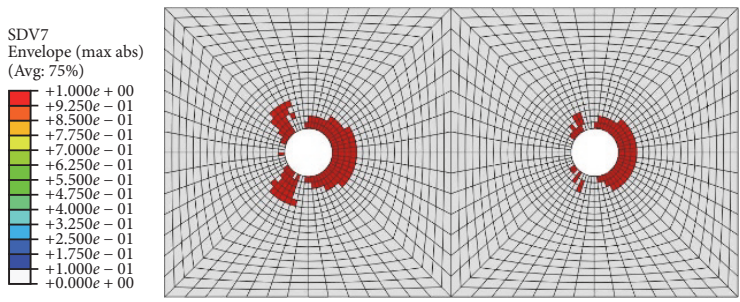

(g) Fiber-matrix shear-out failure (SDV7)

FIGURE 8: Damage envelope of various failure modes under ultimate load.

when $\beta$ is no more than 3 degrees (see Table 6 ). The variations of all curves, from linear elastic segment to the nonlinear segment, are also consistent, which indicates that hole perpendicularity error has a minimal impact on mechanical performance of this kind of joints, while, for P2 and P3, there is a significant decline with increasing of $\beta$. When $\beta=2$, the stiffness decreases by nearly $12 \%$. The largest decline of joint stiffness happens in $\mathrm{P} 4$, which is about $23.8 \%$ even when $\beta=2$. It is easy to understand that $\mathrm{P} 4$ experiences twice the influence of hole perpendicularity error of $\mathrm{P} 2$.

Figure 9(f) shows the comparison of different joint patterns with $\beta=4$. The only difference between $\mathrm{P} 1$ and $\mathrm{P} 2$, as well as $\mathrm{P} 4$ and $\mathrm{P} 5$, is tilting direction $\alpha$. However, the stiffness of $\mathrm{P} 1$ and $\mathrm{P} 5$ is higher than that of $\mathrm{P} 2$ and $\mathrm{P} 4$, respectively. It can be concluded that when hole tilts against the load direction $\left(\alpha=0^{\circ}\right)$, hole perpendicularity error has less influence on joint stiffness than that of $\alpha=180^{\circ}$. Detailed comparison results are shown in Figure 10, from which similar conclusions can be drawn.

4.3. Damage Comparison. The appearance of hole perpendicularity error will alter the load transfer path and affect loads transferred by laminates in a single-lap double-bolt joint. The expectant result is obviously that more elements are damaged around the bolt hole when it bears more load. Take tensile load of $30 \mathrm{kN}$ as an example and numerical results of matrix crushing damage are given in Figure 11. Figure 11(a) is the damage nephogram for $\mathrm{P} 0$, which has almost the same scale damage around both holes for each laminate. But, when hole perpendicularity error is involved, element damage becomes severer and uneven, which can be seen by comparing Figures 11(b) and 11(c) with 11(a).

To prove the above conclusion, specimens loaded up to $30 \mathrm{kN}$, about $80 \%$ of the ultimate load, were disassembled 


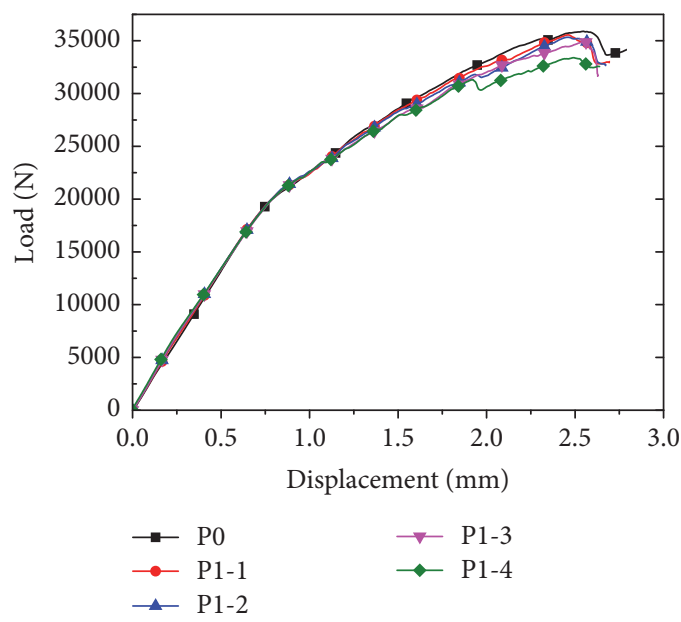

(a) P1
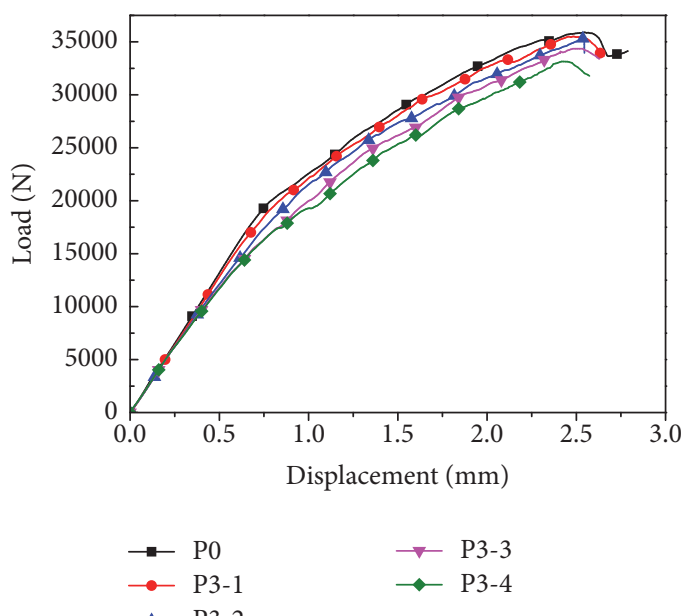

(c) P3

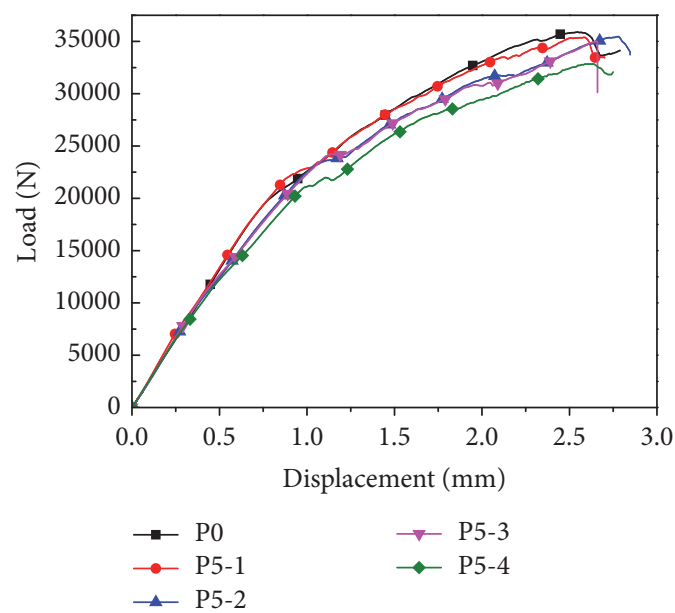

(e) P5

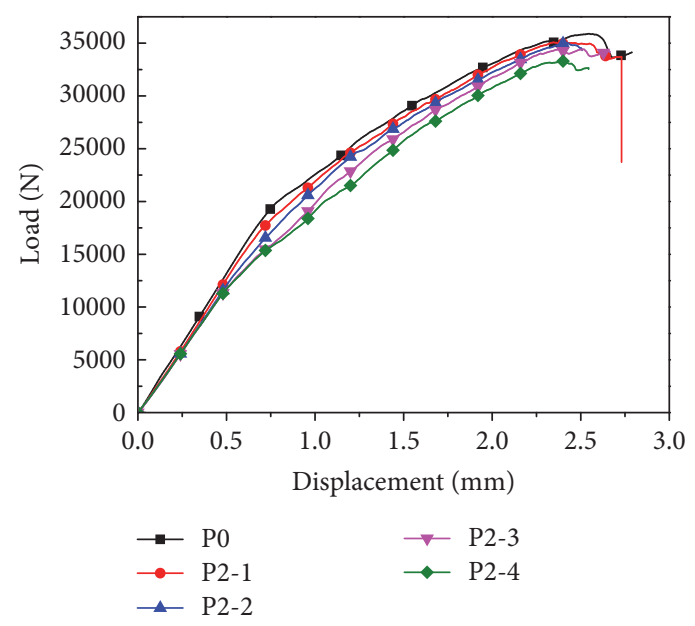

(b) P2

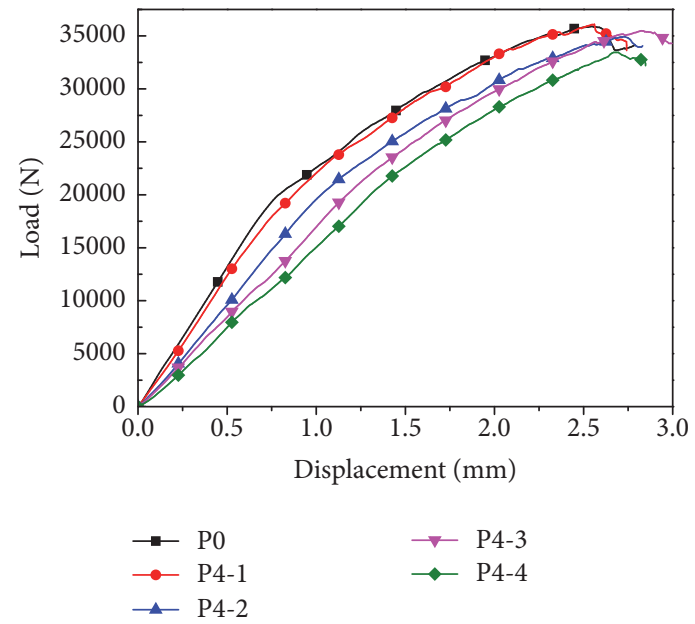

(d) P4

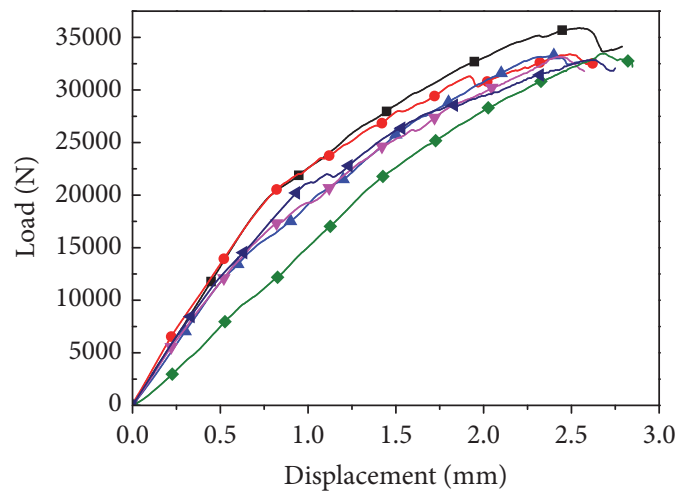

$\begin{array}{ll}\rightarrow \text { P0-0 } & \rightarrow \text { P3-4 } \\ \rightarrow \text { P1-4 } & \rightarrow \text { P4-4 } \\ \longleftarrow \text { P2-4 } & \multimap \text { P5-4 }\end{array}$

(f) Comparison of different joint patterns

FIGURE 9: Numerical results of hole perpendicularity error on joint performance. 
TABLE 6: The stiffness and ultimate load of FEA results.

\begin{tabular}{|c|c|c|c|c|}
\hline Group & Stiffness/N/mm & Decline/\% & Ultimate load/N & Decline $/ \%$ \\
\hline $\mathrm{P} 0$ & 26515 & - & 35901 & - \\
\hline P1-1 & 26325 & 0.72 & 35552 & 0.97 \\
\hline P1-2 & 26061 & 1.71 & 35336 & 1.58 \\
\hline P1-3 & 25751 & 2.88 & 34901 & 2.79 \\
\hline $\mathrm{P} 1-4$ & 25187 & 5.01 & 33394 & 6.98 \\
\hline P2-1 & 25154 & 5.13 & 35077 & 2.30 \\
\hline P2-2 & 23389 & 11.79 & 35052 & 2.36 \\
\hline P2-3 & 21805 & 17.76 & 34419 & 4.13 \\
\hline P2-4 & 21482 & 18.98 & 33302 & 7.24 \\
\hline P3-1 & 25327 & 4.48 & 35506 & 1.10 \\
\hline P3-2 & 23453 & 11.55 & 35353 & 1.53 \\
\hline P3-3 & 22015 & 16.97 & 34088 & 4.28 \\
\hline P3-4 & 22005 & 17.01 & 33182 & 7.57 \\
\hline P4-1 & 25090 & 5.4 & 35558 & 0.96 \\
\hline P4-2 & 20203 & 23.8 & 35429 & 1.31 \\
\hline P4-3 & 16926 & 36.2 & 34675 & 3.41 \\
\hline P4-4 & 15501 & 41.5 & 33441 & 6.85 \\
\hline P5-1 & 26161 & 1.3 & 35388 & 1.43 \\
\hline P5-2 & 23667 & 10.7 & 35453 & 1.25 \\
\hline P5-3 & 23185 & 12.5 & 35013 & 2.47 \\
\hline P5-4 & 21140 & 20.3 & 32830 & 8.55 \\
\hline
\end{tabular}

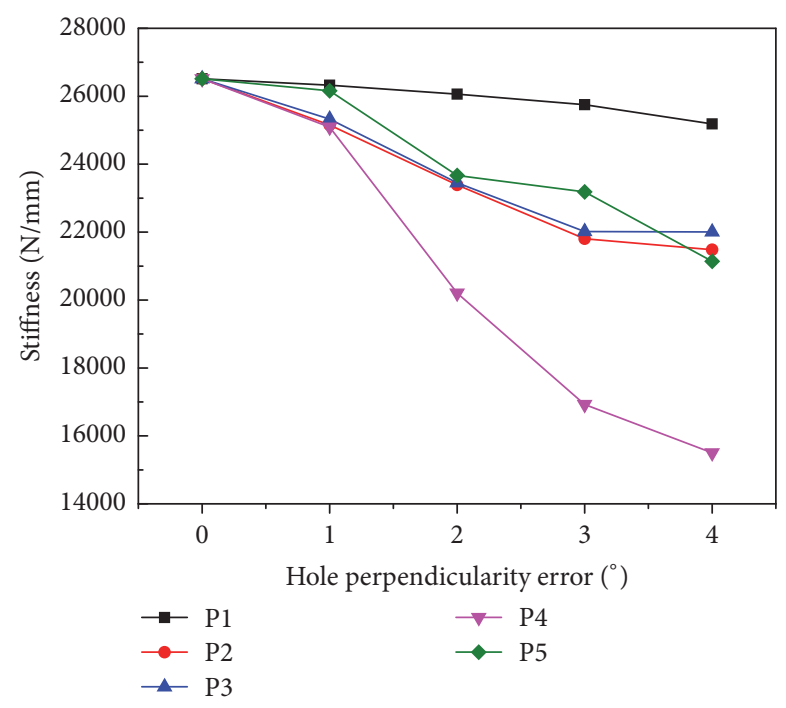

FIGURE 10: The influence of hole tilting direction on joint stiffness.

to observe the damage around the holes. Pictures captured by optical microscope are shown in Figure 12, where first row is the results of $\mathrm{P} 0$, second row is the results of $\mathrm{P} 1$ with $\beta=4$, the last row is the results of $\mathrm{P} 2$ with $\beta=4$, A-1 indicates the left hole of top laminate, and B-2 represents the hole of bottom laminate for each configuration. Obviously, the damage of $\mathrm{P} 2$ is severer than that of $\mathrm{P} 1$ and $\mathrm{P} 0$. The damage of $\mathrm{P} 0$ and $\mathrm{P} 1$ has only minor differences, which proves that the parameter $\alpha=180^{\circ}$ has less influence on the joint than that of $\alpha=0^{\circ}$. Taking the damage location and degree into consideration, numerical results show a good agreement with the experimental ones.

\section{Conclusions}

(1) A progressive damage model based on Chang-Lessard criterion was implemented using UMAT subroutine of ABAQUS/standard to predict damage initiation, evolution, and ultimate failure of single-lap double-bolt composite joint. Seven modes of failures are captured to forecast the internal damage of the composite laminates. The prediction of failure for composite bolt joints shows good agreement with experimental results.

(2) The bolt hole tilting angle up to $4^{\circ}$ has little impact on ultimate bearing load of single-lap double-bolt composite joints. However, the stiffness is apparently affected. The stiffness of $\mathrm{P} 2$ and $\mathrm{P} 3$ decreases rapidly with increase of tilting angle.

(3) By loading up to $30 \mathrm{kN}$, the damage of P2 is severer than that of $\mathrm{P} 1$, which proves that the initial damage of $\mathrm{P} 2$ will occur under relatively less amount of load. When composite bolt joints are subjected to tensile load, hole tilting against 


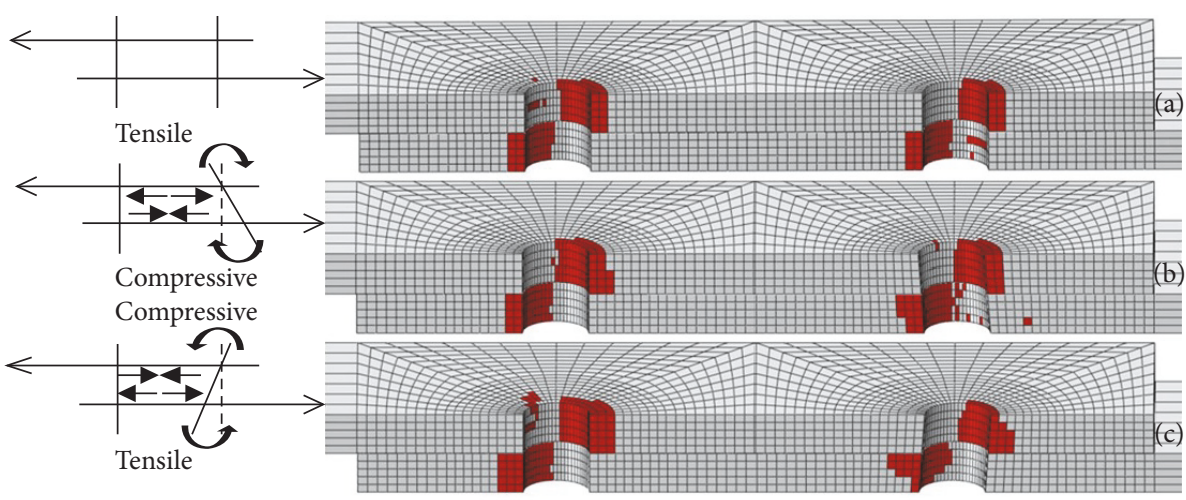

FIGURE 11: Load transfer path and damage of matrix crushing failure.

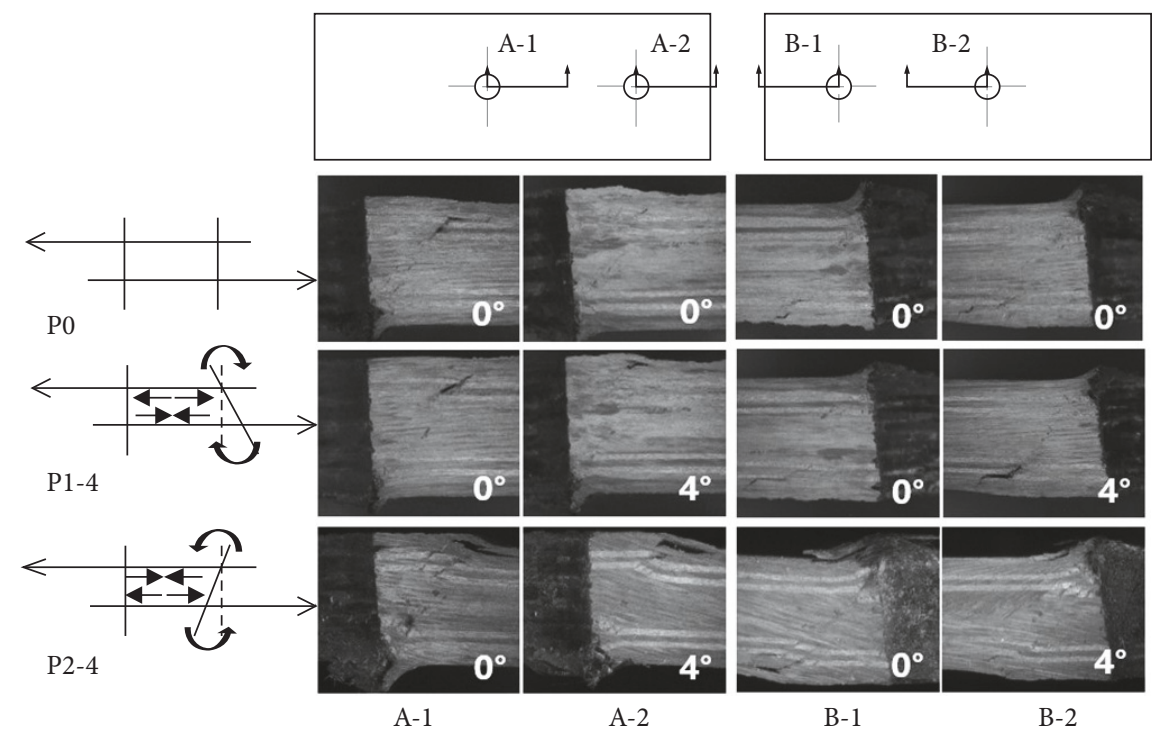

Figure 12: Hole damage pictures for specimen loaded up to $30 \mathrm{kN}$.

loading direction $\left(\alpha=0^{\circ}\right)$ should be more concerned and avoided.

\section{Conflicts of Interest}

The authors declare that there are no conflicts of interest regarding the publication of this paper.

\section{Acknowledgments}

This work was supported by the National Natural Science Foundation of China (Grant nos. 51375068 and 51475073), the Major State Basic Research Development Program (Grant no. 2014CB046504), the Fundamental Research Funds for the Central Universities (Grant no. DUT17JC19), and the Scientific Research Foundation for the Returned Overseas Chinese Scholars, State Education Ministry.

\section{References}

[1] R. Hazimeh, R. Othman, K. Khalil, and G. Challita, "Influence of plies' orientations on the stress distribution in adhesively bonded laminate composite joints subjected to impact loadings," Composite Structures, vol. 152, pp. 654-664, 2016.

[2] T. E. A. Ribeiro, R. D. S. G. Campilho, L. F. M. da Silva, and L. Goglio, "Damage analysis of composite-aluminium adhesivelybonded single-lap joints," Composite Structures, vol. 136, pp. 2533, 2016.

[3] S. Budhe, M. D. Banea, S. de Barros, and L. F. M. da Silva, "An updated review of adhesively bonded joints in composite materials," International Journal of Adhesion and Adhesives, vol. 72, pp. 30-42, 2017.

[4] A. Valenza, V. Fiore, C. Borsellino, L. Calabrese, and G. Di Bella, "Failure map of composite laminate mechanical joint," Journal of Composite Materials, vol. 41, no. 8, pp. 951-964, 2007.

[5] C. Cooper and G. J. Turvey, "Effects of joint geometry and bolt torque on the structural performance of single bolt tension 
joints in pultruded GRP sheet material," Composite Structures, vol. 32, no. 1-4, pp. 217-226, 1995.

[6] P. J. Gray, R. M. O'Higgins, and C. T. McCarthy, "Effect of thickness and laminate taper on the stiffness, strength and secondary bending of single-lap, single-bolt countersunk composite joints," Composite Structures, vol. 107, no. 1, pp. 315324, 2014.

[7] A. Riccio and L. Marciano, "Effects of geometrical and material features on damage onset and propagation in single-lap bolted composite joints under tensile load: Part I - Experimental studies," Journal of Composite Materials, vol. 39, no. 23, p. 2071, 2005.

[8] G. Kolks and K. I. Tserpes, "Efficient progressive damage modeling of hybrid composite/titanium bolted joints," Composites Part A: Applied Science and Manufacturing, vol. 56, pp. 51-63, 2014.

[9] S. Heimbs, S. Schmeer, J. Blaurock, and S. Steeger, "Static and dynamic failure behaviour of bolted joints in carbon fibre composites," Composites Part A: Applied Science and Manufacturing, vol. 47, no. 1, pp. 91-101, 2013.

[10] C. T. McCarthy, M. A. McCarthy, and V. P. Lawlor, "Progressive damage analysis of multi-bolt composite joints with variable bolt-hole clearances," Composites Part B: Engineering, vol. 36, no. 4, pp. 290-305, 2005.

[11] C. T. McCarthy and M. A. McCarthy, "Three-dimensional finite element analysis of single-bolt, single-lap composite bolted joints. Part II. Effects of bolt-hole clearance," Composite Structures, vol. 71, no. 2, pp. 159-175, 2005.

[12] H. Gao, J. Wang, Y. Yang et al., "Effect of hole perpendicularity error on mechanical behavior of single-lap composite joints," Astronautica Sinica, vol. 02, pp. 285-293, 2017.

[13] ASTM standard D 5961/D 5961M-96, Standard Test Method for Bearing Response of Polymer Matrix Composite Laminates, 1996.

[14] Abaqus-Inc., Abaqus analysis user's guide, Version 6.14, 2014, http://50.16.225.63/v6.14/books/usb/default.htm?startat= pt06ch28.html.

[15] F.-K. Chang and K.-Y. Chang, "A Progressive Damage Model for Laminated Composites Containing Stress Concentrations," Journal of Composite Materials, vol. 21, no. 9, pp. 834-855, 1987.

[16] S. W. Tsai and E. M. Wu, "A general theory of strength for anisotropic materials," Journal of Composite Materials, vol. 5, pp. 58-80, 1971.

[17] Z. Hashin, "Failure criteria for unidirectional fiber composites," Journal of Applied Mechanics, vol. 47, no. 2, pp. 329-334, 1980.

[18] A. Puck and H. Schürmann, "Failure analysis of FRP laminates by means of physically based phenomenological models," Composites Science and Technology, vol. 58, no. 7, pp. 1045-1067, 1998.

[19] F.-K. Chang and L. B. Lessard, "Damage tolerance of laminated composites containing an open hole and subjected to compressive loadings. Part I. Analysis," Journal of Composite Materials, vol. 25 , no. 1, pp. 2-43, 1991.

[20] Á. Olmedo and C. Santiuste, "On the prediction of bolted single-lap composite joints," Composite Structures, vol. 94, no. 6, pp. 2110-2117, 2012.

[21] S. C. Tan, "Progressive failure model for composite laminates containing openings," Journal of Composite Materials, vol. 25, no. 5, pp. 556-577, 1991.

[22] F.-K. Chang and K.-Y. Chang, "Post-Failure Analysis of Bolted Composite Joints in Tension or Shear-Out Mode Failure," Journal of Composite Materials, vol. 21, no. 9, pp. 809-833, 1987.

[23] P. P. Camanho and F. L. Matthews, "A progressive damage model for mechanically fastened joints in composite laminates,"
Journal of Composite Materials, vol. 33, no. 24, pp. 2248-2280, 1999.

[24] C. T. McCarthy, R. M. O’Higgins, and R. M. Frizzell, “A cubic spline implementation of non-linear shear behaviour in three-dimensional progressive damage models for composite laminates," Composite Structures, vol. 92, no. 1, pp. 173-181, 2010.

[25] K. I. Tserpes, G. Labeas, P. Papanikos, and T. Kermanidis, "Strength prediction of bolted joints in graphite/epoxy composite laminates," Composites Part B: Engineering, vol. 33, no. 7, pp. 521-529, 2002. 

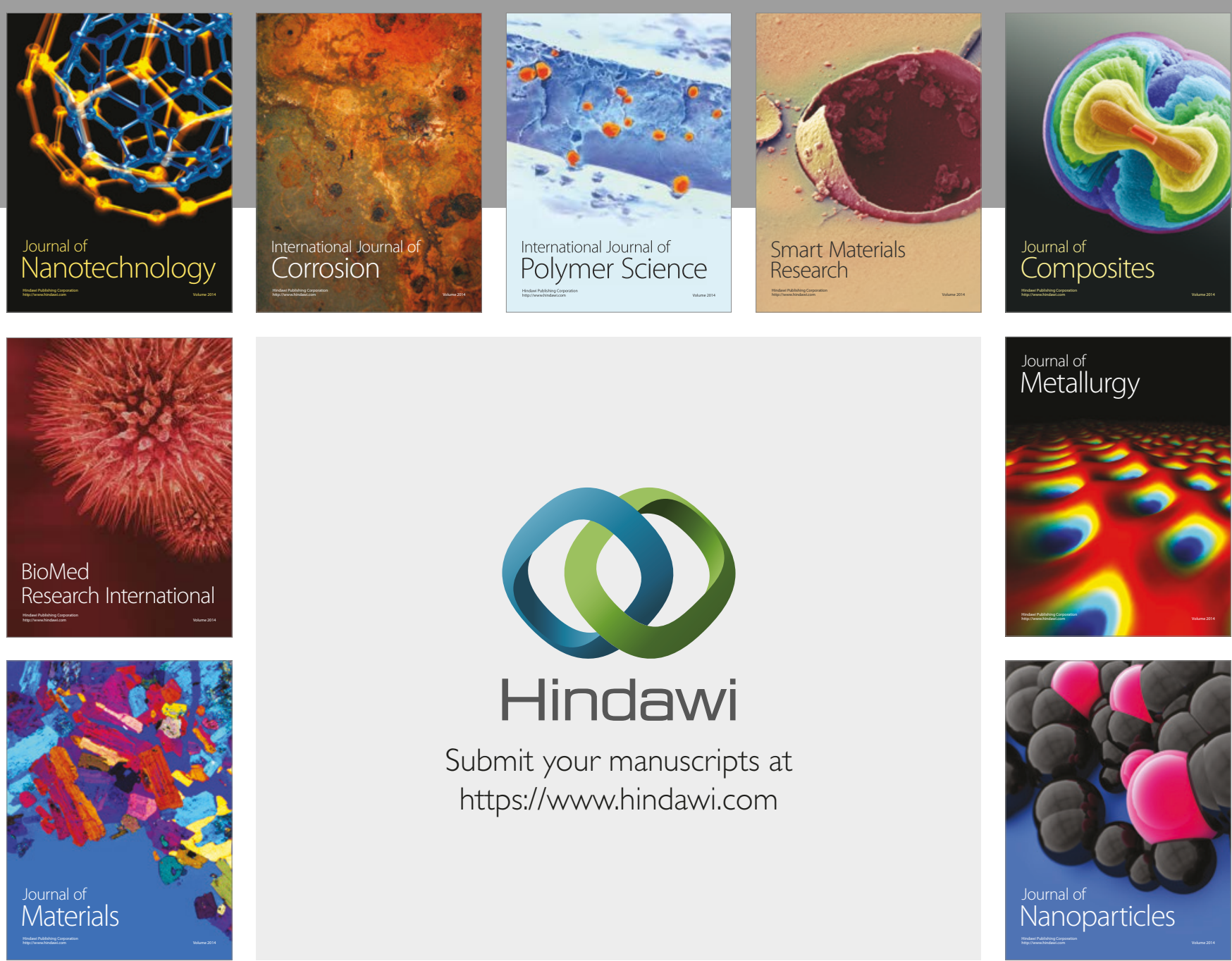

\section{Hindawi}

Submit your manuscripts at

https://www.hindawi.com
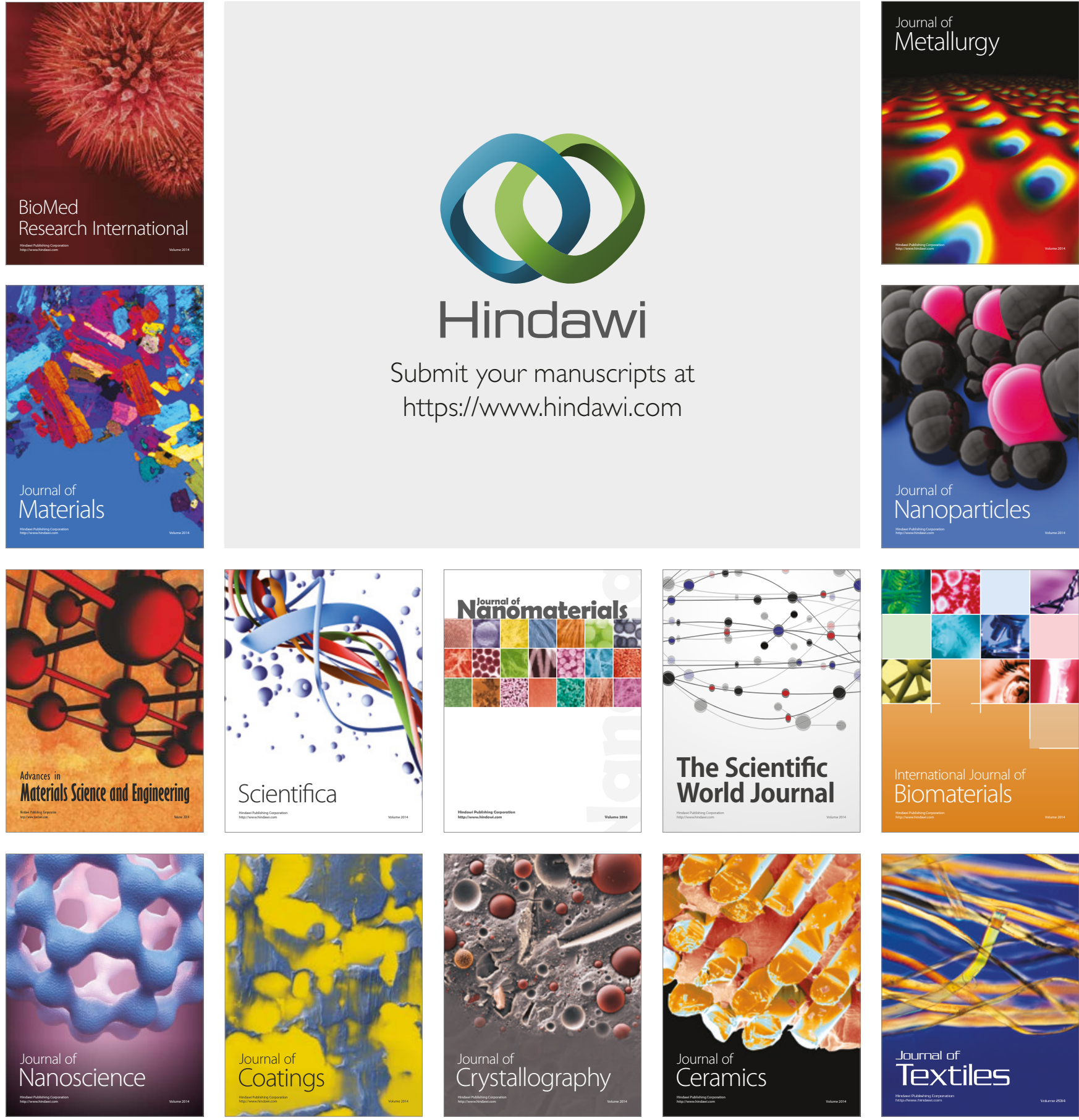

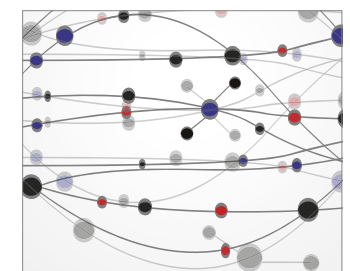

The Scientific World Journal
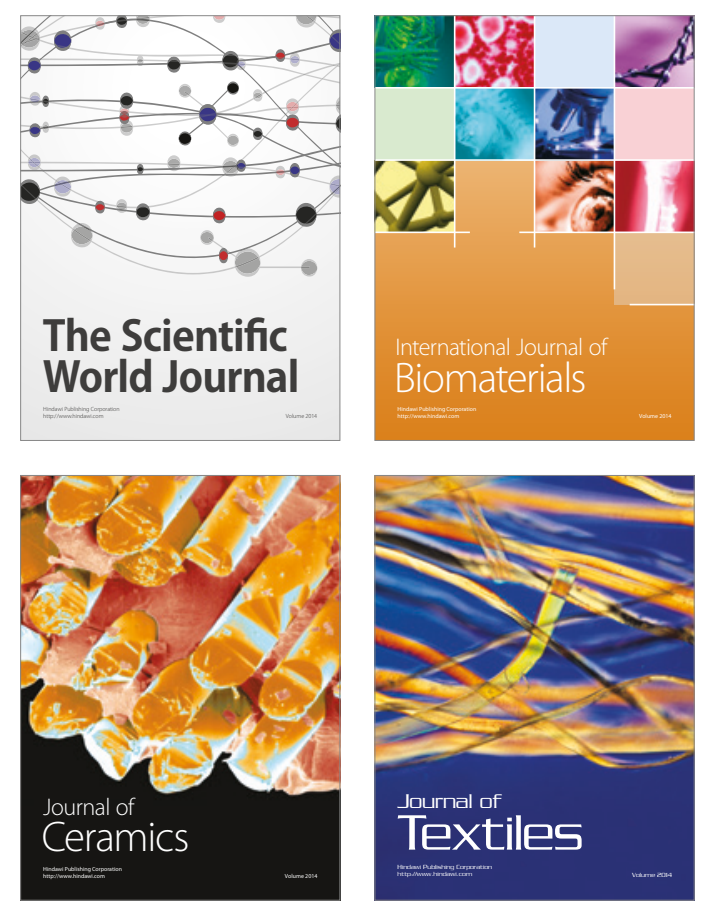